\title{
Normal Molecular Weight of Type VII Collagen Produced by Recessive Dystrophic Epidermolysis Bullosa Keratinocytes
}

\author{
Mark Jenison, Jo-David Fine, W. Ray Gammon, and Edward J. O'Keefe \\ Department of Dermatology, University of North Carolina, Chapel Hill, North Carolina, U.S.A.
}

Studies of the recessive dystrophic form of epidermolysis bullosa (RDEB) have suggested that an abnormality in type VII collagen may be involved in the pathogenesis of this disorder. Indirect immunofluorescence studies have shown that the staining for type VII collagen along the dermal-epidermal junction is markedly reduced or absent in all but rare cases of severe, generalized RDEB. These findings imply that the genetic defect may involve type VII collagen but do not exclude the possibility that the alterations demonstrated are secondary, for example, to nonspecific proteolysis of type VII collagen. To evaluate the ability of cells of affected patients to produce type VII collagen, we cultured keratinocytes from a severely affected patient and immunoprecipitated type VII collagen from the cells. Keratinocytes were metabolically labelled with ${ }^{35} \mathrm{~S}$-methionine, and solubilized cell extracts were reacted with antibody to type VII collagen. The results indicate that the patient's keratinocytes synthesize type VII collagen and that the $\mathrm{M}_{\mathrm{r}}$ of the protein synthesized does not differ from that of an unaffected control. Because cultured cells from a patient severely affected with recessive dystrophic epidermolysis bullosa produce type VII collagen, the genetic defect, at least in this patient, is unlikely to reside in a major truncation of the type VII collagen molecule. J Invest Dermatol 100:93-96, 1993

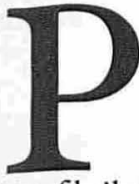

earson was the first to note that patients with severe, generalized forms of recessive dystrophic epidermolysis bullosa (RDEB) have an abnormal ultrastructure at the dermal-epidermal junction [1]. It was later confirmed that these distinctive fibrillar structures, named anchoring fibrils [2], were either absent or markedly reduced in number in patients with RDEB [3]. Other studies have subsequently confirmed these findings $[4,5]$. Type VII collagen was later found to be the major component of the anchoring fibril [6-8], and immunofluorescence studies using antibodies directed against type VII collagen have confirmed that type VII collagen appears to be reduced or absent within unblistered skin from patients with severe generalized RDEB [9-14].

Although type VII collagen has been implicated by inference in such studies as the possible etiologic defect in severe, generalized $\mathrm{RDEB}$, the mechanism of the abnormality has not as yet been fully investigated. For example, it is not known whether patients with severe generalized RDEB express normal or reduced amounts of a mutant form of type VII collagen or have reduced amounts of a structurally normal type VII collagen, or, alternatively, whether the observed reduction in type VII collagen is a reflection of enhanced proteolysis secondary either to a structurally altered form of type

Manuscript received March 26, 1992; accepted for publication October 6, 1992.

Reprint requests to: Dr. Edward O'Keefe, 137 NCMH, CB 7600, Department of Dermatology, University of North Carolina, Chapel Hill, NC 27514.

Abbreviations:

BSA: bovine serum albumin

EBA: epidermolysis bullosa aquisita

HBSS: Hank's buffered saline solution

RDEB: recessive dystrophic epidermolysis bullosa

SDS: sodium dodecyl sulfate
VII collagen or to excessive amounts of collagenase [15-17]. To examine the production of type VII collagen in RDEB, we have examined the protein produced by keratinocytes by metabolic labeling and immunoprecipitation. Our studies indicate that the protein is produced and appears to be normal in some respects.

\section{MATERIALS AND METHODS}

Antibodies We used the ammonium sulfate-precipitated fraction (IgG $=1.24 \mathrm{mg} / \mathrm{ml}$ ) from the serum of a patient with epidermolysis bullosa acquisita to immunoprecipitate type VII collagen from extracts of cultured cells. This antibody is known to identify the noncollagenous domain of type VII collagen [18] and was a gift of Dr. D. Woodley. Rabbit anti-fibronectin has been characterized previously [19].

Cell Culture and Metabolic Labeling Keratinocytes were obtained from the truncal skin of a severely affected adult patient with the Hallopeau-Siemens form of generalized RDEB (gravis form) [20] and, as a control, from a normal adult. The patient with RDEB and her two affected brothers were treated for many years at this institution. All three affected individuals had experienced marked growth retardation, severe anemia, esophageal strictures, mutilating mitten-like deformities of the hands and feet, severe intraoral disease activity with scarring, and recurrent squamous cell carcinomas of the skin. In the case of our patient, squamous cell carcinoma metastasized and was directly responsible for her death. Indirect immunofluorescence on this patient's skin using monoclonal antibody LH 7:2 [9] to type VII collagen at 1:40 dilution, which readily demonstrates the protein in normal skin, failed to demonstrate staining for type VII collagen at the dermal-epidermal junc-
tion (not shown). 
Keratinocytes were obtained and initiated into culture according to the method of Rheinwald and Green [21]. Both normal and RDEB keratinocytes were then subcultured in MCDB 153 medium with appropriate supplements (using a modification [22] of the method of Boyce and Ham [23]) and passaged six times (normal keratinocytes) or seven times (RDEB keratinocytes) to remove any contaminating fibroblasts. Cells were grown to near confluence in 35-mm petri dishes, washed three times with Hanks' balanced saline solution (HBSS), and incubated for $1 \mathrm{~h}$ at $37^{\circ} \mathrm{C}$ in methioninefree MCDB 153 with all other appropriate supplements. The media in all petri dishes were then replaced with methionine-free MCDB 153 containing $50 \mu \mathrm{Ci}^{35} \mathrm{~S}$-methionine (Trans-label 51006; ICN, Irvine, CA) per $\mathrm{ml}$ and incubated at $37^{\circ} \mathrm{C}$ for $18 \mathrm{~h}$.

All subsequent steps were carried out at $4^{\circ} \mathrm{C}$. After the medium was decanted from each petri dish, the cell layers were washed three times with HBSS containing $0.1 \mathrm{mM} \mathrm{Ca}^{++}$and then incubated for $2 \mathrm{~min}$ in $1 \mathrm{ml}$ of $0.1 \mathrm{M}$ Tris- $\mathrm{HCl}, \mathrm{pH} 6.8$, containing $0.5 \%$ Nonidet P-40, $0.5 \%$ sodium deoxycholate, $0.1 \%$ SDS, $1 \mathrm{mM}$ ethylenediamine tetraacetate, and $2 \mathrm{mM}$ phenylmethylsulfonyl fluoride (RIPA buffer). The cells and buffer were then scraped off the dish, vortexed for $1 \mathrm{~min}$, sonicated for $30 \mathrm{sec}$, and centrifuged at $100,000 \times g$ for $30 \mathrm{~min}$. The extracts were diluted in RIPA buffer to $2-8 \times 10^{6} \mathrm{cpm} / \mathrm{ml}$.

Immunoprecipitation Procedures Immunoprecipitation of type VII collagen was carried out essentially according to procedures described previously [24] using the extracts prepared as described above. Samples were pre-incubated with antifibronectin antibody to remove fibronectin, because without this procedure radiolabeled fibronectin in the samples bound nonspecifically to protein A-Sepharose and obscured the type VII collagen band.

Protein A-bearing staphylococci (Pansorbin; Calbiochem, La Jolla, CA) were washed in 9 vol of $10 \mathrm{mM}$ sodium phosphate

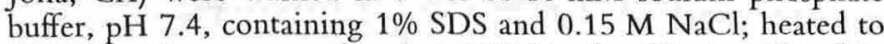
$60^{\circ} \mathrm{C}$ for $15 \mathrm{~min}$; centrifuged at $2000 \times \mathrm{g}$ for $15 \mathrm{~min}$; diluted in $10 \mathrm{mM}$ glycine containing $2 \mathrm{M}$ urea and $1 \%$ Triton $\mathrm{X}-100$; washed three times by centrifugation in $10 \mathrm{mM}$ sodium phosphate buffer containing $0.1 \mathrm{M} \mathrm{NaCl}, 1 \mathrm{mM}$ EDTA, $0.1 \%$ Triton X-100, and $1 \mathrm{mM} \mathrm{NaN}_{3}$; and stored at $10 \%(\mathrm{v} / \mathrm{v})$ in this buffer.

Each 1-ml sample of cell extract described above was pre-absorbed for $3 \mathrm{~h}$ at $4^{\circ} \mathrm{C}$ on a rotating wheel with $10 \mu \mathrm{l}$ normal human serum, $10 \mu \mathrm{l}$ rabbit anti-human fibronectin serum, and $122 \mu \mathrm{l} 10 \mathrm{X}$ extraction buffer ( $6 \%$ Nonidet P-40, 3\% sodium deoxycholate, $2.35 \mathrm{M} \mathrm{NaCl}, 1 \%$ bovine serum albumin, $0.02 \%$ sodium azide in tris-buffered saline (TBS) [0.01 M Tris-HCl, pH 7.4, 0.15 M $\mathrm{NaCl}]$ ) in a $1.5-\mathrm{ml}$ Eppendorf tube. The samples were then transferred to fresh $1.5-\mathrm{ml}$ Eppendorf tubes containing the extensively washed pellet from $0.5 \mathrm{ml}$ of $10 \%$ Pansorbin, incubated for $90 \mathrm{~min}$ on a rotating wheel at $4^{\circ} \mathrm{C}$, and centrifuged in a Beckman Microfuge 12 at full speed for $5 \mathrm{~min}$. The supernatant was divided into two $0.5-\mathrm{ml}$ aliquots and transferred to fresh $1.5-\mathrm{ml}$ Eppendorf tubes containing $40 \mu \mathrm{l}$ anti-type VII collagen antibody or $10 \mu \mathrm{l}$ control serum, incubated at $4^{\circ} \mathrm{C}$ for $16 \mathrm{~h}$, and centrifuged for $5 \mathrm{~min}$ at full speed in a Beckman Microfuge. The supernatant was transferred to a fresh tube containing $100 \mu \mathrm{l}$ Sepharose CL-4B coupled to protein A (Sigma Chemical Corp., St. Louis, MO) and incubated for $30 \mathrm{~min}$ at room temperature and then for $1 \mathrm{~h}$ at $4^{\circ} \mathrm{C}$ on a rotating wheel. Samples were washed three times with $1 \mathrm{ml}$ washing buffer $(0.3 \%$ Nonidet P-40, $0.3 \%$ sodium deoxycholate, $0.5 \mathrm{M} \mathrm{NaCl}, 0.02 \%$ $\mathrm{NaN}_{3}, 0.01 \mathrm{M}$ Tris-HCl, $\mathrm{pH} 7.4$ ) containing $0.1 \%$ bovine serum albumin, three times with $1 \mathrm{ml}$ washing buffer, and once with distilled water. Samples were then transferred to fresh tubes and aspirated to dryness with a 27 -gauge needle. The Sepharose beads were suspended in $2 \times$ Laemmli sample buffer [25], heated to $75^{\circ} \mathrm{C}$ for $3 \mathrm{~min}$, and centrifuged briefly in a Beckman Microfuge. Equal volumes of the supernatants were analyzed by SDS polyacrylamide gel electrophoresis on $5 \%$ polyacrylamide gels [25]. The gels were dried and fluorographed with Kodak X-Omat film using Fluorohance autoradiography enhancer (RPI Corp., Mt. Prospect, IL) ac-

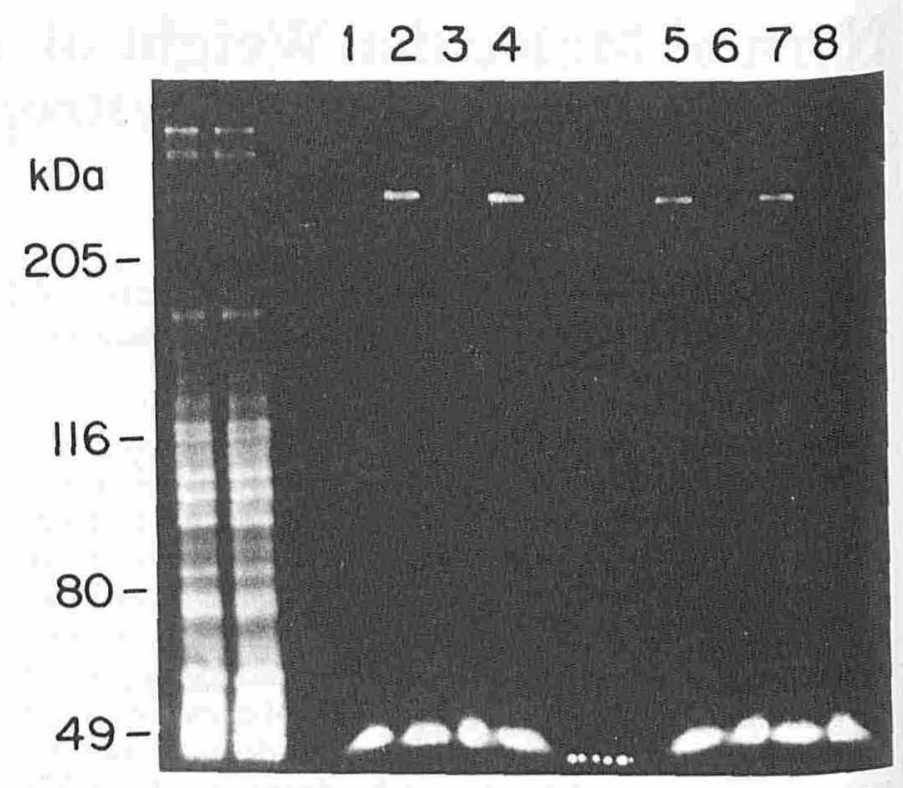

Figure 1. Molecular weight of type VII collagen from RDEB and normal keratinocytes. Keratinocytes were metabolically labeled and type VII collagen was immunoprecipitated, as in Materials and Methods. Lanes 1-4, normal keratinocyte control; lanes 5-8, RDEB keratinocytes. Antibody to type VII collagen was used in lanes $2,4,5,7$; control serum was used in lanes $1,3,6,8$. The two unmarked lanes at the left show labeled extracts from normal keratinocytes before immunoprecipitation. Molecular weight standards are shown at left.

cording to the manufacturer's instructions. Contact prints were made from the autoradiograms.

\section{RESULTS}

Figure 1 shows a $290-\mathrm{kDa}$ band representing the major protein immunoprecipitated from extracts of ${ }^{35} \mathrm{~S}$-labeled normal cells in our experiments (lanes 2,4 ). This band was not present in lanes in which control serum had been used (lanes 1,3 ) and was therefore specifically immunoprecipited by the antiserum to type VII collagen. These results are comparable to previous work using this antiserum $[18,26]$ and indicate that type VII collagen was immunoprecipitated under the conditions of our experiments.

Figure 1 also shows the immunoprecipitate of metabolically labeled type VII collagen from a patient with RDEB (lanes 5 and 7). As in the case of the normal cells, control antiserum did not appear to precipitate any proteins (lanes 6 and 8 ). The bands of type VII collagen from a severely affected patient with RDEB did not differ in mobility from the control. In this experiment, therefore, type VII collagen from RDEB keratinocytes cannot be distinguished from that from normal cells by its mobility on SDS gels. This suggests that if type VII collagen is abnormal in these conditions, it is not substantially altered with respect to the length of the polypeptide chain. The results established clearly that in at least one pedigree with severe, generalized RDEB, type VII collagen is produced in vitro. The gene for type VII collagen is therefore present and transcribed, and mRNA is translated.

There is a reduction in the amount of type VII collagen immunoprecipitated from the affected cells in our experiments, but the significance of this result cannot be established based upon our experiments with the cells of a single RDEB patient. Such a result may depend on growth characteristics of the cells in culture or other factors; the determination of whether a reduction in the quantity of type VII collagen produced by RDEB cells is significant in our experiments will require comparison with results using cells from a 
large number of other RDEB patients. It is interesting to note that there was no apparent proteolysis of the $290-\mathrm{kDa}$ band by the RDEB cells with the production of lower molecular weight fragments in our experiments. The finding of others of two bands identified by antibody to type VII collagen on immunoblots from skin of a patient with RDEB inversa [27] is suggestive of proteolysis, which could be a feature of the disease or secondary to it. It will be of interest to determine whether metabolically labeled type VII collagen from other RDEB parients or from patients with the inversa and centripetalis forms of RDEB who also appear to have alterations in type VII collagen $[14,28,29]$ differs from that of our patient.

Our results do not exclude the possibility that type VII collagen is involved in the pathogenesis of RDEB. First, deletion of even a substantial number of amino acids might not be apparent in our studies. Second, the type VII collagen produced could be normal in size but functionally abnormal. Because collagen must bind to other matrix proteins, its binding functions may be significantly altered. Post-translational modifications of the polypeptide could also be defective. Such modifications, either in primary structure or in glycosylation or phosphorylation, for example, might also render it unusually susceptible to proteolysis. Susceptibility to proteolysis may indeed explain the moderate to drastic reductions in type VII collagen described in immunofluorescence studies. Third, a reduction in the quantity of type VII collagen produced may reduce the functional integrity of the anchoring fibrils. Finally, evidence is strong that inheritance of a related disorder, dominant dystrophic epidermolysis bullosa, is closely linked to the gene for type VII collagen [30].

\section{DISCUSSION}

Because our study used keratinocytes, it was of interest to address the question of the origin of type VII collagen in the skin. Both keratinocytes and dermal fibroblasts can synthesize type VII collagen [31 - 33]. Briggaman and Wheeler [3] showed that recombinant skin containing dermis from an RDEB patient and normal epidermis reproduced the phenotype, abnormal anchoring fibrils, when cultured on a chick chorioallantoic membrane, whereas normal dermis combined with RDEB epidermis did not; they suggested that the abnormality in anchoring fibrils depends in some way on the dermis. Recent work, however, provides evidence that the specific collagen molecules making up anchoring fibrils may be derived from the epidermis $[34,35]$. Although the question may not be resolved at present, it is possible, if not likely, that type VII collagen in the cutaneous basement membrane, like fibronectin [36], originates in the epidermis. Because antibodies to type VII collagen identify the protein from both keratinocytes and dermal fibroblasts $[31-33]$, it is possible that both molecules represent the same gene product.

Additional studies will be required to determine whether abnormalities in the primary structure or post-translational modifications are present in RDEB type VII collagen. Recent cDNA cloning of type VII collagen [37] will facilitate the determination of its primary structure in RDEB. Our experiments suggest that a major truncation of the protein or severe reduction in synthesis is not likely to be responsible for the demonstrated abnormalities in the skin and, if defective type VII collagen underlies RDEB, that small deletions or, more likely, point mutations may be demonstrated. The possibility that the protein is rapidly degraded in vivo cannot be ruled out, but this was not apparent in vitro. Additional studies will be required to determine whether minor modifications in the RDEB type VII collagen might be demonstrated by measurements of isoelectric points or susceptibility to proteolytic cleavage and to determine whether heterogeneity of type VII collagen expression is demonstrable by immunoprecipitation using cells from additional patients. These results do demonstrate definitively, however, that the production of type VII collagen by keratinocytes is compatible with the RDEB phenotype.
This work was supported by NIH grants AR25837 to EO'K, AR34861 to JD Fine, and AR30475 to WR Gammon.

\section{REFERENCES}

1. Pearson R: Studies on the pathogenesis of epidermolysis bullosa. J Invest Dermatol 39:551-575, 1962

2. Palade G, Farquhar M: A special fibril of the dermis. J Cell Biol 27:215-224, 1965

3. Briggaman RA, Wheeler CE: Epidermolysis bullosa dystrophic-recessive: a possible role of anchoring filaments in the pathogenesis. $J$ Invest Dermatol 65:203-211, 1975

4. Hashimoto I, Schnyder UW, Anton-Lamprecht I, Gedde-Dahl T Jr, Ward S: Ultrastructural studies in epidermolysis bullosa hereditaria: III. Recessive dystrophic types with dermolytic blistering (Hallopeau-Siemens types and inverse type). Arch Dermatol Res 256:137 - 150, 1976

5. Tidman MJ, Eady RAJ: Evaluation of anchoring fibrils and other components of the dermal-epidermal junction in dystrophic epidermolysis bullosa by a quantitative technique. J Invest Dermatol $84: 374-377,1985$

6. Sakai LY, Keene DR, Morris NP, Burgeson RE: Type VII collagen is a major structural component of anchoring fibrils. J Cell Biol 103:1577-1586, 1986

7. Lunstrum GP, Sakai LY, Keene DR, Morris NP, Burgeson RE: Large complex globular domains of type VII procollagen contribute to the structure of anchoring fibrils. J Biol Chem 261:9042-9048, 1986

8. Keene DR, Sakai Y, Lunstrum GP, Morris NP, Burgeson RE: Type VII collagen forms an extended network of anchoring fibrils. J Cell Biol 104:611-621, 1987

9. Heagerty AHM, Kennedy AR, Leigh IM, Purkis P, Eady RAJ: Identification of an epidermal basement membrane defect in recessive forms of dystrophic epidermolysis bullosa by $\mathrm{LH} \mathrm{7:2} \mathrm{monoclonal}$ antibody: use in diagnosis. $\mathrm{Br}$ J Dermatol 115:125 - 131, 1986

10. Leigh IM, Eady RAJ, Heagerty AHM, Purkis P, Whitehead PA, Burgeson RA: Type VII collagen is a normal component of epidermal basement membrane which shows altered expression in recessive dystrophic epidermolysis bullosa. J Invest Dermatol 90:639-642, 1988

11. Bruckner-Tuderman L, Ruegger S, Odermatt B, Mitsuhashi Y, Schnyder UW: Lack of type VII collagen in unaffected skin of patients with severe recessive dystrophic epidermolysis bullosa. Dermatologica 176:57-64, 1988

12. Rusenko KW, Gammon WR, Fine JD, Briggaman RA: The carboxylterminal domain of type VII collagen is present at the basement membrane in recessive dystrophic epidermolysis bullosa. J Invest Dermatol 92:623-627, 1989

13. Bruckner-Tuderman L, Mitsuhasshi Y, Schnyder UW, Bruckner P: Anchoring fibrils and type VII collagen are absent from skin in severe recessive dystrophic epidermolysis bullosa. J Invest Dermatol 93:3-9, 1989

14. Fine JD, Johnson LB, Wright T: Type VII collagen and 19-DEJ-1 antigen: comparison of expression in inversa and generalized variants of recessive dystrophic epidermolysis bullosa. Arch Dermatol 126:1587-1593, 1990

15. Eisen AZ: Human skin collagenase: relationship to the pathogenesis of epidermolysis bullosa dystrophica. J Invest Dermatol 52:449-453, 1969

16. Bauer EA: Abnormalities in collagenase expression as in vitro markers for recessive dystrophic epidermolysis bullosa. J Invest Dermatol
$79: 105 S-108 S, 1982$

17. Stricklin GP, Welgus HG, Bauer EA: Human skin collagenase in recessive dystrophic epidermolysis bullosa: purification of a mutant enzyme from fibroblast cultures. J Clin Invest 69:1373 - 1383, 1982

18. Woodley DT, Burgeson RE, Lunstrum G, Bruckner-Tuderman L, Reese MJ, Briggaman RA: The epidermolysis bullosa acquisita antigen is the globular carboxyl terminus of type VII procollagen. J Clin
Invest 81:683-687, 1988

19. O'Keefe EJ, Woodley D, Castillo G, Russell N, Payne RE Jr: Production of soluble and cell-associated fibronectin by cultured keratinocytes. J Invest Dermatol 82:580-586, 1984 
20. Fine JD, Bauer EA, Briggaman RA, et al: Revised clinical and laboratory criteria for subtypes of inherited epidermolysis bullosa: a consensus reported by the Subcommittee on Diagnosis and Classification of the National Epidermolysis Bullosa Registry. J Am Acad Dermatol 24:119-135, 1991

21. Rheinwald JG, Green H: Serial cultivation of strains of human epidermal keratinocytes: the formation of keratinizing colonies from single cells. Cell 6:331 - 344, 1975

22. O'Keefe EJ, Chiu ML: Stimulation of thymidine incorporation in keratinocytes by insulin, epidermal growth factor, and placental extract: comparison with cell number to assess growth. J Invest Dermatol 90:2-7, 1988

23. Boyce ST, Ham RG: Calcium-regulated differentiation of normal human epidermal keratinocytes in chemically defined clonal culture and serum-free serial culture. J Invest Dermatol 81(suppl 1):33-40, 1983

24. Petersen MJ, Woodley DT, Stricklin GP, O'Keefe EJ: Production of procollagenase by cultured human keratinocytes. J Biol Chem 262:835-840, 1987

25. Laemmli UK: Cleavage of structural proteins during assembly of the head of bacteriophage T4. Nature 227:680-685, 1970

26. Woodley DT, Briggaman RA, O'Keefe EJ, Inman AO, Queen LL, Gammon WR: Identification of the skin basement membrane autoantigen in epidermolysis bullosa acquisita. N Engl J Med 310:1007-1013, 1984

27. Bruckner-Tuderman L, Rantala I, Reunala T: Evidence for a structural abnormality of collagen VII in a patient with dystrophic epidermolysis bullosa inversa. J Invest Dermatol 98:141 -146, 1992

28. Bruckner-Tuderman L, Niemi KM, Kero M, Schnyder UW, Reunala T: Type-VII collagen is expressed but anchoring fibrils are defective in dystrophic epidermolysis bullosa inversa. $\mathrm{Br} \mathrm{J}$ Dermatol 122:383-390, 1990

29. Fine JD, Osment LS, Gay S: Dystrophic epidermolysis bullosa: a new variant characterized by progressive symmetrical centripetal involvement with scarring. Arch Dermatol 121:1014-1017, 1985

30. Ryynanen M, Knowlton RG, Parente MG, Chung LC, Chu M-L, Uitto J: Human type VII collagen: genetic linkage of the gene (COL7A1) on chromosome 3 to dominant dystrophic epidermolysis bullosa. Am J Human Genet 49:797-803, 1991

31. Stanley JR, Rubinstein N, Klaus-Kovtun V: Epidermolysis bullosa acquisita antigen is synthesized by both human keratinocytes and human dermal fibroblasts. J Invest Dermatol 85:542-545, 1985

32. Woodley DT, Briggaman RA, Gammon WR, O'Keefe EJ: Epidermolysis bullosa acquisita antigen is synthesized by human keratinocytes cultured in serum-free medium. Biochem Biophys Res Comm 130:1276-1272, 1985

33. Woodley DT, Briggaman RA, Gammon WR, Falk RJ, Reese MJ, Tomsick RS, O’Keefe EJ: Epidermolysis bullosa acquisita antigen, 3 major cutaneous basement membrane component, is synthesized by human dermal fibroblasts and other cutaneous tissues. J Invest Dermatol 87:227-231, 1986

34. Regauer S, Seiler GR, Barrandon Y, Easley KW, Compton CC: Epithelial origin of cutaneous anchioring fibrils. J Cell Biol 111:21092115, 1990

35. Ryynanen J, Sollberg S, Parente MG, Chung LC, Christiano AM, Uitto J: Type VII collagen gene expression by cultured human cells and in fetal skin: abundant mRNA and protein levels in epidermal keratinocytes. J Clin Invest 89:163 - 168, 1992

36. O'Keefe EJ, Woodley DT, Falk RJ, Gammon WR, Briggaman RA: Production of fibronectin by epithelium in a skin equivalent. J Invest Dermatol 88:634-639, 1987

37. Parente MG, Chung LC, Ryynänen J, Woodley DT, Bauer E, Chu M-L, Uitto J: Human type VII collagen - cDNA cloning and chromosomal mapping of the gene. Proc Natl Acad Sci USA 88:69316935,1991 